\title{
MANTRA PETAPA ALAS PURWO: KAJIAN SEMIOTIKA RIFFATERRE
}

\section{THE ASCETIC SPELL IN ALAS PURWO: RIFFATERRE SEMIOTIC ANALYSIS}

\author{
M. Fawaid Al Fikry ${ }^{1}$, Sunarti Mustamar ${ }^{2 *}$, Christanto Pudjirahardjo ${ }^{3}$ \\ ${ }^{1}$ Alumni Fakultas Ilmu Budaya, Universitas Jember \\ ${ }^{2,3}$ Fakultas Ilmu Budaya, Universitas Jember \\ ${ }^{*}$ Corresponding Author: sunartimustamar1959@gmail.com \\ Informasi Artikel:
}

Dikirim: 1/02/2019; Direvisi: 10/03/2019; Diterima: 5/04/2019

\begin{abstract}
Mantra (spell) is the oldest poem in oral literature used as a kind of prayer and hope to God through His creation. This research goals to describe the structure and meaning of the text found in Alas Purwo spells entitled "Restoring magic" using Riffaterre's semiotic theory. Qualitative methods and descriptive analysis are used as research method. The analysis is focused on structural analysis of themes and diction, followed by Riffaterre's semiotic analysis to discuss four things, namely the unsustainability of expression, heueristic and hermeneutic readings, matrices or keywords, and hypograms or intertexts. The results showed that the theme of the mantra is the wish from spell practitioner delivered to the Lord of the universe, while the diction is denotative and connotative. The unsustainable expression in the form of replacement of meaning is found in the use of the synecdoche; deviation of the meaning of the spell, found in the nonsense language style; while the creation of the meaning of spell is dominated by homologues. Heuristic reading uses Indonesian conventions, while hermeneutic reading shows the hope of the spell reader to return the evil magic to its owner. The matrix or keyword in the spell lies in "tekobi bae bae wong kang seja ala maring ingsun", moreover the spell hypogram is based on verses of the Koran. The meaning of the spell is by having supernatural power, someone is able to restore evil intentions from others under the Creator's authorization
\end{abstract}

Keywords: Alas Purwo, oral literature, Riffaterre semiotics theory, spell, spirituality

\begin{abstract}
Abstrak
Mantra merupakan puisi tertua dalam sastra lisan yang dimanfaatkan sebagai semacam doa dan harapan kepada Tuhan melalui ciptaan-Nya. Penelitian ini bertujuan untuk mendeskripsikan struktur dan makna teks mantra Alas Purwo berjudul "Mengembalikan sihir" dengan teori semiotika Riffaterre. Metode penelitian menggunakan metode kualitatif dan analisis deskriptif. Analisis tersebut difokuskan pada analisis struktural terhadap tema dan diksi, dilanjutkan analisis semiotika Riffaterre dengan cakupan empat hal, yakni ketidaklangsungan ekspresi, pembacaan heueristik dan hermeneutik, matriks atau kata kunci, dan hipogram atau interteks. Hasil penelitian menunjukkan bahwa tema mantra adalah harapan pengamal mantra kepada Tuhan pengatur alam semesta, sedangkan diksi bersifat denotatif dan konotatif. Ketidaklangsungan eksprsi berupa penggantian arti terdapat pada penggunaan gaya bahasa sinekdoke; penyimpangan arti mantra, terdapat pada gaya bahasa nounsense; sedangkan penciptaan arti mantra, didominasi oleh homologues. Pembacaan heuristik menggunakan konvensi bahasa Indonesia, sedangkan pembacaan hermeneutik menunjukkan harapan pembaca mantra
\end{abstract}




\begin{abstract}
untuk mengembalikan sihir jahat kepada pemiliknya. Matriks atau kata kunci dalam mantra terletak pada tekobi bae bae wong kang sejo olo mreng ingson, sedangkan hipogram mantra bersumber dari ayat suci Al-Quran. Makna mantra tersebut adalah dengan kekuatan supranatural, seseorang dapat mengembalikan niat jahat dari orang lain atas seizin Sang Pencipta.
\end{abstract}

Kata kunci: Alas Purwo, sastra lisan, semiotika Rifatterre, mantra, spiritual

\title{
PENDAHULUAN
}

Karya sastra lisan di Indonesia dikenal satu bentuk karya sastra bergenre puisi yaitu mantra. Dalam genre khasanah puisi Indonesia, mantra dikategorikan sebagai bentuk puisi tertua. Mantra juga dapat diartikan sebagai doa dan harapan kepada Tuhan melalui penciptaan jin, malaikat, nabi dan rasul bahkan merujuk kepada entitas tertinggi makrokosmos maupun mikrokosmos yaitu Tuhan. Keberadaan mantra dalam masyarakat tradisional di Indonesia menyatu secara inheren dengan kehidupan sehari-hari. Kegiatan yang sering dilakukan oleh masyarakat tradisional dan berhubungan dengan karya sastra lisan berupa mantra adalah kebiasaan bertapa yang disertai dengan pembacaan mantra. Kebiasaan tersebut didasarkan oleh adanya kepercayaan di tengah masyarakat tentang suatu berkah yang dapat diperoleh dari merapalkan atau pembacaan mantra tertentu. Mereka meyakini bahwa pembacaan mantra merupakan wujud dari sebuah usaha untuk mencapai keselamatan dan kesuksesan sesuai dengan yang diharapkan. Oleh karena itu, keberadaan mantra menjadi penting dan tidak dapat dipisahkan dari kehidupan masyarakat tradisional.

Mantra dan masyarakat mempunyai hubungan yang erat. Artinya, mantra ada karena terdapat masyarakat pewarisnya. Lahirnya mantra di tengah masyarakat merupakan perwujudan suatu keyakinan atau kepercayaan. Kepercayaan terhadap adanya kekuatan gaib yang mendorong masyarakat mengharap terealisasikannya keinginan-keinginan sebagaimana yang menjadi permohonan mereka agar dapat terwujud nyata. Keinginan-keinginan yang umumnya dilatarbelakangi oleh pemenuhan kebutuhan masyarakat, seperti memperoleh berkah, kesehatan, rezeki, keselamatan, terbebas dari bencana.

Mantra pada hakikatnya merupakan metode atau upaya untuk dapat berinteraksi dengan makhluk gaib. Pembaca mantra meyakini bahwa dengan membaca mantra tertentu dapat dipermudah segala harapan dan akan dikabulkan segala keinginannya oleh makhluk gaib yang diyakininya. Hal tersebut diyakini akan terwujud dengan ketentuan mengasihi makhluk gaib atau sering disebut dengan istilah pengasihan. Terdapat banyak jenis teks mantra yang diciptakan dukun dari bahasa Jawa, Arab, Sangsekerta, bahkan bahasa Indonesia (Saputra, 2007). Tidak semua mantra mengasihi Jin atau Setan, terdapat juga mantra yang langsung memohon kepada Tuhan tanpa melalui perantara Jin atau Setan. Artinya dengan membaca mantra dapat menambah keyakinan secara psikis. Sifat magis yang dimiliki mantra menarik untuk dilakukan kajian dari perspektif semiotika. Oleh karena itu, artikel ini membahas mantra Petapa Alas Purwo yang difokuskan pada mantra berjudul "Mengembalikan Sihir" dengan menggunakan teori semiotika Riffatere (1978). Hal ini dilandasi oleh adanya kesamaan bentuk antara mantra dengan puisi. Kajian dilakukan dengan empat model pokok analisis, yaitu ketidaklangsungan ekspresi, pembacaan heueristik dan hermeneutik, matriks atau kata kunci,dan hipogram atau interteks. 


\section{METODE}

Penelitian ini merupakan penelitian lapangan. Metode yang digunakan pada penelitian ini adalah metode kualitatif. Penelitian kualitatif terdiri atas serangkaian praktik material interpretif deskritif dan serangkaian representasi, meliputi data berupa kata-kata atau pernyataan-pernyataan (Denzin dan Lincoln, ed., 2011:3). Metode kualitatif menekankan pada data ilmiah yang bersifat verbal, sehingga dapat digunakan sebagai langkah kerja dalam mengkaji mantra sebagai salah satu karya sastra lisan. Penelitian kualitatif mengutamakan penghayatan untuk memahami interaksi yang terjadi terhadap objek yang dikaji. Metode pengumpulan data dalam peneltian ini menggunakan metode wawancara dengan narasumber atau informan seorang pewaris aktif yang memahami dan menguasai mantra. Informan dalam penelitian ini adalah seorang pewaris aktif, berusia relatif tua, menjadi pelaku mantra (menjalani laku mistik), dan banyak menjalani laku mistik di Alas Purwo. Alas Purwo terletak di wilayah bagian Selatan di Kabupaten Banyuwangi.

Analisis dalam penelitian ini menggunakan analisis struktural berupa tema dan diksi, sedangkan analisis semiotika Riffaterre dengan empat model pokok yaitu, ketidaklangsungan ekspresi, pembacaan heuristik dan hermeneutik, matriks atau kata kunci, dan hipogram atau interteks. Analisis struktural dan analisis semiotika tersebut bermuara pada pemaknaan terhadap mantra.

\section{HASIL DAN PEMBAHASAN}

Hasil penelitian dapat dipaparkan sebagai berikut. Informan yang berhasil dihubungi dan bersedia untuk diwawancarai adalah Mbah Bustami, seorang petapa di Alas Purwo yang berasal dari daerah Tegaldlimo. Mbah Bustami bertapa di wilayah yang dikenal sebagai tempat favorit untuk tirakat para wong pinter dari berbagai wilayah di Nusantara tersebut bertujuan untuk mendapatkan wangsit yang diyakininya dapat digunakan sebagai sarana dalam menyelesaikan persoalan dalam kehidupan kesehariannya. Dalam pandangan para sesepuh yang menjalani laku mistik si sana, Alas Purwo adalah 'alas wiwitan' atau 'kawitan' yang dipahami sebagai tempat asal mula kehidupan atau sumber ngelmu paling awal. Oleh karena itu, dalam pandangan mereka, orang yang menjalani laku mistik merasa belum afdol kalau belum menjalaninya di Alas Purwo.

Berdasarkan ekplorasi data dari Mbah Bustami, diperoleh lima judul mantra, yakni "Mengembalikan Sihir", "Lembu Sekilan", "Pamungkase Rasa", "Kasampurnan", dan "Sulaiman". Mantra-mantra tersebut bukan hanya dihafalkan, melainkan juga diterapkan atau dilaksanakan dalam kehidupan keseharian.

Mengingat ruang artikel yang terbatas, untuk kajian ini difokuskan pada mantra yang telah disebutkan pertama, yakni "Mengembalikan Sihir". Mantra tersebut dalam konteks ini dipersepsi telah mewakili yang lain, sehingga analisis difokuskan pada satu mantra tesebut. Hasil dan pembahasan terhadap mantra "Mengembalikan Sihir" dapat diformulasikan dalam paparan tentang dimensi struktural dan dimensi semiotisnya. Dimensi struktural menekankan upaya untuk mengungkap tema dan diksi, sedangkan dimensi semiotis menekankan pada tanda-tanda estetis hasil kreasi pencipta mantra (anonim) atas potensi bahasa lokal terkait dengan konteks kultural dan nilai-nilai supranatural. Pembahasan tersebut diformulasikan pada paparan berikut 


\section{Analisis Struktural}

Langkah awal dalam sebuah penelitian karya sastra adalah dengan menggunakan analisis struktural. Menurut Abram (dalam Nurgiyantoro, 2005:36) bahwa struktur karya sastra diartikan sebagai susunan atau gambaran semua bahan dan bagian yang menjadi komponen karya sastra secara bersama membentuk kebulatan yang indah. Analisis struktural merupakan kajian kesusastraan yang menitikberatkan pada hubungan antarunsur pembangun karya sastra. Dalam hal tersebut karya sastra memiliki unsur yang bersistem, yang unsurnya terjadi hubungan timbal balik dan saling menentukan. Mantra "Mengembalikan Sihir" dibahas pada unsur tema dan diksi. Pembatasan pembahasan unsur dalam penelitian ini karena kedua unsur tersebut sangat dominan dalam mantra tersebut.

\section{Tema}

Mantra atau puisi memiliki gagasan pokok atau subjectmatter untuk dikemukakan atau ditonjolkan. Hal tersebut dipengaruhi oleh falsafah hidup, lingkungan agama, dan pekerjaan. Menurut Waluyo (2002:17), tema merupakan gagasan pokok yang dikemukakan oleh penyair. Tema dalam puisi harus memiliki makna yang akan membentuk tema puisi sehingga tema puisi merupakan pikiran utama penyair dalam puisinya atau ide pokok yang ingin disampaikan seorang penyair kepada penikmatnya.

Mantra berjudul "Mengembalikan Sihir" bertema harapan pengamal mantra kepada Tuhan pengatur alam semesta untuk menghindarkan dirinya dari orang lain yang ingin berbuat jahat kepadanya dengan mengirimkan sihir maupun sejenisnya. Artinya, jika ada orang lain yang punya rencana jahat kepada pengamal mantra, baik berupa sihir atau pun sejenisnya, akan cepat dikembalikan kepada orang yang berbuat jahat tersebut. Dengan demikian tujuannya agar pengamal mantra terhindar dari perbuatan jahat dengan mengharap pertolongan dari Tuhan YME sebagai pengatur alam semesta.

Harapan pengamal mantra disampaikan melalui mantra yang berjudul "Mengembalikan Sihir". Hal tersebut dapat diketahui dari kutipan sebagian data mantra berikut.

ora tumeka wong kang gawe ala maring ingsun

ora tumeka wong kang gudha rencana ala maring ingsun

bingung bingung bingung sangking Allah Ta'ala

Baris tersebut menunjukkan bahwa pengamal mantra berharap sihir yang ditujukan kepada pengamal mantra akan dikembalikan oleh Tuhan Yang Maha Esa. Hal ini dikarenakan bahwa Tuhan YME merupakan pengatur alam semesta. Pemilik jagad yang memiliki kekuatan yang tidak ada siapa pun yang sanggup mengalahkan-Nya. Kekuatan yang dimiliki oleh Tuhan YME inilah yang menjadi dasar keyakinan dari pengamal mantra untuk memohon agar bisa terhindar dari perbuatan jahat orang lain yang memang bermaksud mencelakakan dirinya dengan mengirimkan sihir atau sejenisnya. Harapan dari pengamal mantra dengan kekuatan makrokosmos dan mikrokosmos inilah, pengamal mantra meyakini hanya kekuatan Tuhan YME yang sanggup mengembalikan sihir yang ditujukan kepadanya. Artinya, ada keyakinan spiritual bahwa dengan memohon kepada Tuhan YME, maka segala daya kekuatan yang jahat dan merusak dapat ditanggalkan dan dikembalikan kepada pihak-pihak yang akan 
melakukan kejahatan sihir kepada pengamal mantra.

\section{Diksi}

Diksi berarti pilihan kata yang tepat, padat, kaya akan nuansa makna sehingga mampu mengembangkan dan mempengaruhi daya imajinasi pembaca. Menurut Tarigan (1984:29), diksi adalah "pilihan kata". Pilihan kata yang menarik dapat menggugah bagi penikmat karya sastra. Kata dipilih dan disusun sedemikian rupa, dimaksudkan untuk menimbulkan imaji estetik, selain itu untuk mendapatkan unsur kepuitikan. Unsur diksi dibagi menjadi dua bagian yaitu denotasi dan konotasi.

Kata-kata denotasi. Denotasi merupakan makna kata yang sebenarnya. Menurut Altenbernd (dalam Pradopo, 1997:58) denotasi adalah kata yang merujuk pada bentuk/hal yang diberi nama kata itu, disebutkan, dan diceritakan. Penggunaan kata denotasi dalam satu sajak memberikan kemudahan bagi pembaca dalam memahami sajak tersebut. Penggunaan kata denotatif diawali dari judul mantra yaitu "Mengembalikan sihir". Judul mantra tersebut mengandung arti adanya keinginan dari pengamal mantra untuk mengembalikan niat jahat orang lain kepada dirinya. Hal tersebut dapat dicermati pada kutipan sebagian data berikut.

\section{Alloh lenggah ingsun alip \\ Tekobe bae-bae wong kang seja ala maring ingsun \\ Ora tumeka wong kang gawe ala maring ingsun}

Kata-kata tersebut merupakan pilihan kata yang bersifat denotatif. Penggunaan kata denotatif mengacu pada keinginan terwujudnya upaya mengembalikan rencana jahat orang lain kepada dirinya. Penggunaan kata denotatif ini bertujuan agar keinginan atau tujuan pengamal mantra langsung diketahui oleh pembaca serta dapat membuat pengamal mantra lebih percaya dengan mantra yang dilafalkan.

Kata-kata konotasi. Konotasi merupakan pilihan kata yang tidak sesungguhnya. Menurut Pradopo (1997:59), konotasi adalah kumpulan asonansi-asonansi perasaan yang terkumpul dan diperoleh dari setting yang dilukiskan. Kata konotasi penting dipergunakan dalam sebuah karya sastra, terutama dalam puisi. Karya sastra berupa puisi akan terasa kurang nuansa kepuitikannya apabila tidak menyertakan kata-kata konotasi.

Pada data di atas, khususnya pada baris ke-1 yang berbunyi lenggah ingsun alip, merupakan pilihan kata yang memberikan gambaran kesungguhan pengamal mantra dalam mengamalkan mantranya. Dalam mantra "Mengembalikan Sihir" terdapat kata alip, menggambarkan alif yang terdapat pada huruf hijaiyah, yaitu tegak lurus seperti kesungguhan pengamal mantra. Hal tersebut menunjukkan adanya keseriusan pengamal mantra dalam berusaha memohon kepada Tuhan agar mengembalikan niat jahat dari pengirim mantra. Pada baris ke-2 menggambarkan ada orang yang mengirimkan sihir kepada pengamal mantra. Kemudian pada baris ke-3 pengamal mantra ingin mengembalikan sihir kepada pemiliknya dengan restu dari Allah. Pengamal mantra memahami bahwa segala sesuatu sudah diatur oleh Tuhan. Dalam baris mantra tersebut terdapat diksi yang menggunakan kata konotatatif dan menggunakan bunyi berat sehingga membuat mantra tersebut mengandung nilai magis dan menambah unsur mistis. Hal ini terdapat pada varian data sebagai berikut: lenggah ingsun 
alip, Bingung bingung bingung sangking Allah Ta'ala. Varian bunyi tersebut menjadi magis dan mistis, karena pilihan diksi yang mengandung bunyi berat atau kakofoni dapat menimbulkan makna mantra yang kuat akan unsur mistisnya. Apalagi ditambah dengan diksi pada baris berikutnya tekobe bae bae wong kang seja ala maring ingsun, ora tumeka wong kang gawe ala maring ingsun. Diksi denotatif pada baris tersebut di atas merupakan penegasan dari diksi baris sebelumnya. Penggunaan kata konotatif atau kiasan atau simbolsimbol yang dipadu dengan pemilihan bunyi kakofoni membuat mantra menjadi terasa magis dan mistis.

Dengan demikiam, pemilihan diksi juga menjadi faktor yang sangat penting dalam memberikan daya magis dan mistis dari suatu mantra. Kekuatan diksi konotatif yang berupa simbol-bimbol atau kiasan dikombinasikan dengan penggunaan bunyi kakofoni dalam mantra "Mengembalikan Sihir" mampu memberikan daya magis dan mistis. Daya magis dan mistis dari ekspresi yang diperlihatkan pada pemilihan diksi dalam konteks karya mantra menunjukkan nuansa kepuitikannya dari mantra tersebut. Nuansa kepuitikan yang memiliki daya magis dan mistis serta sarat akan pesan-pesan yang ingin disampaikan oleh pengamal mantra.

\section{Analisis Semiotika Riffaterre}

Teori semiotika yang digunakan untuk menganalisis kumpulan mantra yaitu teori semiotika menurut Michael Riffaterre (1978). Di dalam teori tersebut Riffaterre mengemukakan empat hal pokok dalam memproduksi makna puisi. yakni meliputi ketidaklangsungan ekspresi, pembacaan heuristik dan hermeneutik, matriks atau kata kunci, dan hipogram atau interteks. Berikut penerapan empat hal pokok tersebut.

\section{Ketidaklangsungan Ekspresi}

Puisi merupakan ekspresi tidak langsung. Ketidaklangsungan ekspresi tersebut menurut Riffaterre (dalam Pradopo, 1997:210) disebabkan oleh tiga hal yaitu penggantian arti (displacing of meaning), penyimpangan arti (distorting of meaning), dan penciptaan arti (creating of meaning).

Penggantian arti (displacing of meaning). Penggunaan arti pada puisi disebabkan oleh penggunaan majas metafora dan majas metonimia. Metafora dipakai dalam mantra tersebut sebagai usaha pengarang dalam memenuhi unsur ketidaklangsungan ekspresi. Di samping menggunakan diksi denotatif dalam mantra tersebut juga menggunakan diksi konotatif atau bahasa kiasan (figurative language), meliputi simile, personifikasi, dan sinekdoke. Penggantian arti yang terdapat pada mantra "Mengembalikan Sihir" adalah sebagai berikut.

"Mantra Mengembalikan Sihir"

Bismillahirrohmanirrohim kulhu bismillahirrohmanirrohim kulhuwallohuahad

kunfayakun masyaallah wabirohmatika, bismillahirohmanirohim kulhu sung sang raja iman petengku nuntun Nabi Muhammad, yahu ngundur Allah, 


\begin{abstract}
lungguh ingsun alip,
tekobi bae bae wong kang seja ala maring ingsun,

ora tumeka wang kang gawe ala maring ingsun,

ora tumeka wong kang gudha rencana ala maring ingsun,

bingung bingung bingung sangking Allah SWT,

bismillah kulhu balik sumpah,

balik maring wong kang seja ala maring ingsun,

balik kerana Allah Ta'ala
\end{abstract}

Judul mantra "Mengembalikan Sihir" tersebut menunjukan adanya ketegasan kata pada judul mantra. Mantra tersebut menunjukkan adanya upaya pembaca mengenai sihir atau guna-guna yang menuju kepada dirinya atau orang lain. Tujuannya pembaca mengharapkan dengan membaca atau mengamalkan mantra tersebut dapat mengembalikan mantra atau gunaguna kepada seseorang yang dengan sengaja mengirimkan guna-guna kepada dirinya. Tujuan tersebut diungkapkan dengan kiasan atau melalui simbol-simbol agar mantra tersebut mengandung unsur magis sehingga membuat kata-kata dalam mantra mempengaruhi sugesti pengamal mantra dan menambah keyakinannya terhadap kesaktian mantra tersebut.

Baris pada mantra yang berbunyi bismillahirrohmanirohim kulhu bismillahirohmanirohim menunjukan adanya penggunaan gaya bahasa sinekdoke atau penyebutan sebagian untuk keseluruhan. Kata tersebut bukan hanya mengacu pada bismillahirohmanirohim yang sering dibaca oleh umat muslim pada umumnya untuk mengawali suatu aktivitas dan lain sebagainya. Akan tetapi, pembaca mantra juga dapat menyampaikan rasa syukur dan rasa hormat kepada Allah SWT supaya segala sesuatu dapat terwujud karena izin dari-Nya.

Dengan demikian, bunyi kata bismillahirrohmanirohim mengandung daya kekuatan yang menunjukkan adanya keterwakilan kekuatan dari Tuhan YME akan mampu mengembalikan mantra yang bertujuan jahat kepada peramal mantra. Kata bismillahirrohmanirohim bagi peramal mantra sebagai tanda ekspresi akan keyakinan terhadap kekuatan yang dimiliki oleh Tuhan YME. Hal ini menunjukkan keyakinan simbol atau kiasan akan daya kekuatan magis dan mistis dari mantra yang bertumpu kepada kekuatan Tuhan YME dari penggunaan kata bismillahirrohmanirohim.

Penyimpangan arti (distorting of meaning). Bahasa puisi atau mantra sering menyimpang dari bahasa tertulis atau bahasa normatif pada umumnya (bahasa dalam teks). Menurut Riffaterre (dalam Pradopo, 1997:213) penyimpangan arti terjadi apabila dalam sajak terdapat ambiguitas, kontradiksi, atau pun nonsense. Dalam mantra "Mengembalikan Sihir" terdapat kontradiksi yang menyatakan sesuatu secara kontradiksi atau sebaliknya. Hal tersebut membuat pembaca mantra berpikir sehingga pikiran pembaca mantra terpusat pada persoalan atau inti dari mantra. Ambiguitas adalah kata-kata yang bermakna ganda. Nonsense secara linguistik tidak memiliki arti karena kata-kata tersebut diciptakan oleh penyair atau pencipta mantra untuk mempertegas makna dan menggunakan simbol-simbol tertentu agar pembaca lebih fokus dan serius dalam membacakan mantranya. Nonsense tidak mempunyai makna secara lingustik namun mempunyai makna signifikan dalam puisi karena konvensi puisi. Hal tersebut dapat diketahui pada data berikut.

teka bi bae bae wong kang seja ala maring ingsun, 
ora tumeka wong kang gawe ala maring ingsun, ora tumeka wong kang gudha rencana ala maring ingsun bingung bingung bingung sangking Allah Ta'ala

Pada data mantra yang berbunyi bi bae bae terdapat penggunaan nonsense. Pada frasa tersebut terdapat kata yang secara linguistik tidak memiliki arti, namun secara konvensi mantra mempunyai makna pelengkap terhadap kata selanjutnya. Penggunaan nonsense dalam konteks ini dapat ditafsirkan sebagai sarana untuk memberi kelengkapan bunyi-bunyi yang menimbulkan pencitraan mistis. Artinya, bunyi-bunyi yang nonsense tersebut lebih dimaknai sebagai sarana sugesti untuk memunculkan impresi mistis, sehingga mampu membangun sugesti pembaca mantra atas kekuatan mistis dan dapat diraihnya tujuan yang ingin dicapai dengan media mantra yang mistis tersebut.

Penciptaan arti (creating of meaning). Penciptaan merupakan konvensi kepuitikan yang berupa bentuk visual yang secara linguistik tidak memiliki arti tetapi menimbulkan makna tertentu dalam sajak. Dengan demikian, penciptaan arti merupakan organisasi teks di luar kebahasaan (Riffaterre dalam Pradopo, 1997:220). Penciptaan arti dalam karya sastra meliputi: rima, enjemblemen, homologues, dan tipografi.

Pada data yang telah dikutip sebelumnya, khususnya yang berbunyi Bismillahirrohmanirrohim kulhu bismillahirrohmanirrohim, terdapat homologues, persamaan-persamaan posisi dalam bait. Pada posisi terdapat keseimbangan kesimetrisan berupa persejajaran antara bait-bait atau antara baris-baris dalam bait (Pradopo, 1997:220). Dalam konteks ini, ada perulangan bismillahirrohmanirrohim dalam keseimbangan formasi baris. Hal ini memunculkan kesan melebih-lebihkan dengan harapan mampu membanagun sugesti atas kekuatan mistis. Dengan demikian, bentuk homologues dapat berakibat adannya makna di luar arti kebahasaan.

Hal serupa juga terjadi pada homologues yang lain, yakni pada baris yang berbunyi ora tumeka wong kang gawe ala maring ingsun, dan baris ora tumeka wong kang gudha rencana ala maring ingsun terdapat homologues persamaan-persamaan posisi dalam awal baris. Pada baris yang lain terdapat homologues persamaan-persamaan dalam satu baris, yakni bingung bingung bingung sangking Allah Ta'ala. Pada baris tersebut terdapat persamaan kata dalam satu baris yang berbunyi bingung bingung bingung terdapat persamaan tiga kata dalam satu baris. Dalam konteks ini, homologues tidak berakibat adanya makna di luar arti kebahasaan, karena pengulangan yang terdapat pada mantra tersebut hanya penekanan artikulasi pada mantra. Pembaca mantra dapat menyakini dengan adannya pengulangan tersebut, maka dapat merangsang harapan atau sugesti supaya lebih cepat dikabulkan, dan sihir yang diarahkan akan bingung dan kembali kepada pemiliknya.

\section{Pembacaan Heuristik dan Hermeneutik}

Pembacaan heuristik. Pembacaan heuristik dibaca berdasarkan konvensi bahasa atau sistem bahasa sesuai dengan kedudukan bahasa sebagai sistem semiotika tingkat pertama. Puisi atau mantra dibaca secara linier, artinya dibaca menurut normatif bahasa. Pada umumnya bahasa puisi atau mantra cenderung menyimpang dari penggunaan bahasa biasa atau bahasa normatif (Pradopo, 1997:296). Bahasa yang terdapat dalam puisi tidak 
mengandung arti sesuai dengan arti bahasa sebenarnya. Pembacaan heuristik berfungsi untuk memperjelas arti kebahasaan. Pembacaan heuristik mantra "Mengembalikan sihir" adalah sebagai berikut.

\begin{abstract}
Bismillahirrohmanirrohim,kulhu,bismillahirrohmanirrohim
(Dengan Menyebut Nama Alloh Yang Maha Pengasih Lagi Maha Penyayang) (Katakanlah) (Dengan Menyebut Nama Allah Yang Maha Pengasih Lagi Maha Penyayang) kulhuwallohuahad, kunfayakun, masyaallah, wabirohmatika, (Katakanlah Dia Allah Maha Satu) (jadilah maka jadilah).

bismillahirohmanirohim kulhu, song sang raja iman, petengku nunton Nabi Muhammad, yahu ngundur Allah, (Dengan Menyebut Nama Alloh Yang Maha Pengasih Lagi Maha Penyayang) (Katakanlah) (saya sang raja iman) (gelapku di tuntun Nabi Muhammad, tidak terkecuali Allah) lungguh ingsun alip, (duduk saya huruf alif) tekobi bae bae wong kang seja ala maring ingsun, (datang orang yang berbuat jelek kepada saya) ora tumeka wong kang gawe ala maring ingsun, (tidak sampai orang yang berbuat jelek kepada saya) ora tumeka wong kang gudha rencana ala maring ingsun (tidak sampai orang yang menggoda rencana jelek kepada saya).

bingung bingung bingung sangking Allah Ta'ala, (bingung bingung bingung karena Allah SWT.

bismillah kulhu balik sumpah, (dengan menyebut nama allah. (katakanlah kembali) pulang.) sumpah. balik maring wong kang seja ala maring ingsun, (kembali kepada orang yang berbuat jelek kepada saya). balik kerana Allah Ta'ala. (kembali karena Allah Taala).
\end{abstract}

Pembacaan Hermeneutik. Pembacaan hermeneutik adalah pembacaan ulang dari awal sampai akhir dengan penafsiran atau pembacaan hermeneutik. Pembacaan tersebut dalam pemberian makna berdasarkan konvensi sastra. Menurut Pradopo (1997:135), pembacaan hermeneutik adalah pembacaan ulang dari awal sampai akhir dengan penafsiran. Pembacaan ini dalam pemberian makna berdasarkan konvensi sastra dan budaya. Pembacaan hermeneutik pada mantra "Mengembalikan Sihir" sebagai berikut.

Mantra "Mengembaikan Sihir" merupakan judul mantra yang menunjukan ungkapan atau harapan pembaca untuk mengembalikan sihir jahat kepada pemiliknya. Kata 'Sihir' identik dengan perbuatan gaib seperti guna-guna. Pada baris awal ke-2 berbunyi Bismillahirrohmanirrohimkulhu bismillahirrohmanirrohimkulhuwallohuahad kunfayakun masyaallah wabirohmatika. Pembukaan mantra tersebut menandakan bahwa pembaca mantra mempercayai hakikat Tuhan Allah SWT sebagai tempat atau tujuan untuk meminta perlindungan dan memohon keselamatan. Kata yang digunakan pada mantra tersebut mengisyaratkan ada unsur penggunaan bahasa Arab, pembuat mantra mempercayai segala sesuatu harus diawali dengan pembacaan bismillah, budaya tersebut dapat memberi sugesti tersendiri terhadap kaum muslim.

Pada baris ke-3 sampai akhir, kata yang digunakan pembuat mantra berubah menjadi bahasa Jawa, dan melafalkan Allah sebagai Tuhan yang Maha Esa. Kata sun sang raja iman digunakan dengan menggunakan gaya bahasa metafora mengacu pada pembaca mantra yang merasa taat beriman kepada Allah dan Rosulullah. Pembaca mantra mengharapkan datang orang yang berbuat kejelekan kepada saya, tidak sampai kepada saya sihir jahat yang orang 
lain berikan kepada saya, tidak sampai orang yang merencanakan jelek kepada saya, berharap kepada Allah SWT supaya yang membuat kejelekan kepada saya menjadi bingung, dan saya bersumpah sihir akan kembali kepada pengirimnya karena Allah SWT. Pembaca mengisyaratkan kepada penguasa Alam Semesta Allah SWT bahwa orang yang berbuat jahat, atau merencanakan jahat supaya niat tersebut kembali kepada orang yang hendak berbuat jahat.

\section{Matriks Model dan Varian}

Untuk memahami puisi atau mantra supaya mudah dipahami dan dalam upaya konkretisasi perlu dicari matriks yang ada dalam puisi atau mantra. Matriks adalah kata yang menjadi kunci penafsiran puisi atau mantra yang telah dikonkretisasi. Kata tersebut berhubungan dengan kata lainnya yang ada dalam puisi atau mantra dan menjadi pusatnya (Riffaterre, 1978:19). Jika kata yang menjadi kunci dalam satu puisi atau mantra telah ditemukan maka konkretisasi puisi atau mantra akan menjadi mudah. Matriks berupa suatu tuturan minmal dan harfiah yang selanjutnya ditransformasikan menjadi parafase yang lebih panjang, kompleks, dan tidak harfiah, yakni keseluruhan puisi atau mantra. Matriks tidak terdapat dalam teks, tetapi teraktualisasikan lewat model yang diungkapkan dalam bentuk kiasan. Model tersebut yang akan menentukan bentuk varian atau pengembangan yang akan muncul dalam teks. Model bersifat puitik untuk mengaktifkan kepuitikan dalam teks.

Masalah pokok mantra "Mengembalikan Sihir" terletak pada tekobi bae bae wong kang seja ala maring ingsun, yang artinya datang orang yang berbuat jelek kepada saya. Katakata tersebut adalah kode yang ekuivalen sehingga muncul mantra selanjutnya yang menjadi pendukung kata tersebut, yaitu (1) ora tumeka wong kang gawe ala maring ingsun, (2) ora tumeka wong kang gudha rencana ala maring ingsun, (3) bingung bingung bingung sangking Allah Ta'ala, (4) bismillah kulhu balik sumpah, (5) balik maring wong kang seja ala maring ingsun.

Kode (1) ora tumeka wong kang gawe ala maring ingsun artinya tidak sampai orang yang berbuat jelek kepada saya menunjukkan harapan pembaca mantra untuk hidup di Alam Semesta sejahtera, damai dan tidak ada sihir berbentuk apapun yang dapat mengganggu, sihir tidak akan sampai kepada saya. Kode (2) ora tumeka wong kang gudha rencana ala maring ingsun berarti tidak sampai orang yang menggoda rencana jelek kepada saya menunjukan upaya pembaca mantra supaya tidak sampai seseorang yang menggoda dengan rencana jelek kepada saya, rencana jelek berupa sihir atau guna,guna. Kode (3) bingung bingung bingung sangking Allah Ta'ala artinya adalah bingung bingung bingung karena Allah SWT, terdapat pengulangan kata bingung tiga kali, menandakan niatan pembaca mantra supaya sihir yang diarahkan kepada pembaca mantra pergi atau tidak sampai ke tujuan karena bingung, pengulangan kata tersebut menjadi tanda penekanan yang sungguh-sungguh berharap kepada Tuhan yang Maha Esa Allah SWT. Kode (4) dan kode (5) bismillah kulhu balik sumpah, balik maring wong kang seja ala maring ingsun, mantra ditutup dengan menyebut nama Allah katakanlah pulang sumpah, yaitu dengan menyebut nama Allah pembaca mantra bersumpah mengatakan kembalilah kepada orang yang berbuat jelek sihir kepada saya. 


\section{Hipogram}

Hipogram perlu dikemukakan agar pembacaan hermeneutik lebih optimal. Riffaterre (1978:23) menyatakan bahwa teks yang menjadi latar penciptaan sebuah karya disebut hipogram. Selanjutnya mengutip pendapat Kristiva (dalam Culler, 1977:139) sebagaimana disarankan oleh Riffaterre (1978:91) yang disebut dengan teks tidak hanya berupa tulisan, tetapi juga cerita lisan, adat, tatanan masyarakat, dan bahkan dunia ini adalah teks. Mantra "Mengembalikan Sihir" dilatarbelakangi oleh keinginan pembaca untuk mengembalikan sihir kepada pemiliknya atau pengirimnya melalui bantuan Tuhan Allah SWT. Pada kutipan data yang telah disampaikan sebelumnya, bait pertama baris ke-1 bismillahirrohmanirrohim menginterteks kitab suci Al-Quran, biasanya terdapat pada awal bacaan dalam surah AlQuran. Kulhu berasal dari surah Al-Ikhlas dalam Al-Quran yang diambil dari awal bacaan. Pada baris ke-2 kulhuwallohuahad kunfayakun masyaallah wabirohmatika, mengambil dari ayat suci Al-Quran, seperti kulhuwallohuahad yang artinya katakanlah Dia Allah Maha satu, berasal dari surah Al-Ikhlas yang terdapat pada Ayat pertama. Kemudian kunfayakun masyaallah wabirohmatika, tetap menggunakan kutipan ayat yang terdapat pada Ayat suci Al-Quran. Pada baris ke-3 mantra, bismillahirohmanirohim kulhu sun sang raja iman petengku nunton Nabi Muhammad, yahu ngundur Allah, pada awal mantra menggunakan bismillah dan kulhu potongan dari surah Al-Ikhlas artinya katakanlah, potongan yang terdapat pada kitab suci Al-Quran, kemudian dikombinasikan dengan bahasa Jawa. Pada baris ke-4 lungguh ingsun alip artinya duduk saya alip, alip dimaksudkan adalah alif yang terdapat pada huruf hijaiyah, pembaca mantra mengisyaratkan bahwa pembaca mantra sungguh-sungguh meminta kepada Allah dengan duduk khusyuk tegak seperi huruf Alif yang terdapat pada pengucapan Hijaiyah.

\section{SIMPULAN}

Berdasarkan analisis struktural dan analisis semiotika terhadap mantra Alas Purwo yang berjudul "Mengembalikan Sihir" dapat disimpulkan sebagai berikut. Tema yang terdapat pada mantra tersebut adalah harapan pengamal mantra kepada Tuhan pengatur alam semesta. Diksi yang terdapat pada mantra tersebut merupakan pilihan kata yang menunjukkan gabungan antara yang bersifat denotatif dan konotatif. Analisis semiotika mantra "Mengembalikan Sihir" terdiri atas empat bagian, yaitu (1) ketidaklangsungan ekspresi, (2) pembacaan heuristik dan hermeneutik, (3) matriks, dan (4) hipogram. Ketidaklangsungan eksprsi meliputi penggantian arti, yakni terdapat pada penggunaan gaya bahasa sinekdoke; penyimpangan arti mantra, yakni terdapat pada gaya bahasa nounsense; dan penciptaan arti mantra, yakni didominasi dengan homologues terdapat kesamaan posisi dalam bait. Pembacaan heuristik pada mantra "Mengembalikan Sihir" menggunakan konvensi bahasa Indonesia, sedangkan pembacaan hermeneutik yakni menunjukan ungkapan atau harapan pembaca untuk mengembalikan sihir jahat kepada pemiliknya. Matriks atau kata kunci dalam mantra terletak pada tekobi bae bae wong kang sejo olo mreng ingson yakni kode yang ekuivalen sehingga muncul mantra selanjutnya yang menjadi pendukung kata tersebut, yaitu ora tumeka wong kang gawe ala maring ingsun, (2) ora tumeka wong kang gudha rencana ala maring ingsun, (3) bingung bingung bingung sangking Allah Ta'ala dan ditutup dengan (4) bismillah kulhu balik sumpah, (5) balik maring wong kang seja ala maring ingsun. Mantra 
"Mengembalikan Sihir" berhipogram dari ayat suci Al-Quran dan huruf Hijaiyah yang terdapat dalam bacaan dasar huruf berbahasa Arab. Makna mantra tersebut adalah dengan kekuatan supranatural, seseorang dapat mengembalikan niat jahat dari orang lain atas seizin Sang Pencipta.

\section{DAFTAR PUSTAKA}

Culler, J.1977. Structuralist Poetics. London:Routledge and Keagan Paul.

Denzin, N.K. \& Lincoln, Y.S. (ed). 2011 The Sage Handbook of Qualitative Research 1. Yogyakarta: PustakaPelajar.

Nurgiyantoro. 2005. Teori Pengkajian Fiksi. Yogyakarta: Gadjah Mada University Press.

Pradopo, R.Dj. 1997. Pengkajian Puisi. Yogyakarta: Gadjah Mada University Press.

Riffaterre, M. 1978. Semiotic of Poetry. Bloomington and London. Indiana Universiy Press.

Saputra, H.S.P. 2007. Memuja Mantra: Sabuk Mangir dan Jaran Goyang Masyarakat Suku Using Banyuwangi. Yogyakarta: LKiS.

Tarigan, H.G.1984. Prinsip-prinsip Dasar Sastra. Bandung: Angkasa.

Waluyo, H.J. 2002. Teori Aprersiasi Puisi. Jakarta: Erlangga. 